\title{
A CONFIGURAÇÃo DO MERCADO DAS Folhas Na Pedra em Salvador
}

\author{
Orlando José Ribeiro de OLIVEIRA*
}

RESUMO: Este artigo analisa a configuração do mercado das plantas rituais/ medicinais (folhas) usadas no candomblé de Salvador-BA, considerando a circulação dessas mercadorias produzidas e comercializadas por extrativistas e horticultores que as levam, regularmente, à Feira de São Joaquim, polo distribuidor para outros circuitos do comércio retalhista (feiras, mercados, lojas e bancas de rua). O Mercado da Pedra, uma transação mercantil de grandes quantidades que transcorre na madrugada, foi a base empírica da pesquisa etnográfica que possibilitou a compreensão das estruturas e dos agentes sociais envolvidos na produção, circulação e consumo das folhas que podem resultar de extrativismo ou de horticultura, provindo de hortas e quintais e de manchas florestais remanescentes no entorno de Salvador e interior da Bahia. A singularidade desse mercado revela-se, dentre outros fatores, pela justaposição das esferas da circulação (simples e desenvolvida, segundo Marx) que, de forma dinâmica, articulam um mercado tradicional (africano) ao mercado capitalista contemporâneo.

PALAVRAS-CHAVE: Plantas rituais/medicinais. Mercado. Religiões afrobrasileiras.

\section{Introdução}

Este artigo, baseado em pesquisa empírica, de caráter socio-antropológico, sobre o mercado de plantas rituais em Salvador-BA, tem o objetivo teórico de aplicar a categoria econômica da teoria marxista sobre mercado a um contexto

\footnotetext{
UESB - Universidade Estadual do Sudoeste da Bahia. Departamento de Filosofia e Ciências Humanas. Vitoria da Conquista - BA - Brasil. 45083900 - ojro.furioso@gmail.com.
} 
social tradicional, buscando estabelecer um diálogo interdisciplinar com categorias do debate conceitual econômico-social contemporâneo.

Mercado da Pedra ou Pedra é o nome dado às transações de compra e venda de plantas rituais/medicinais, chamadas de folhas e amplamente consumidas por fiéis do candomblé, que ocorrem em local a céu aberto, na Feira de São Joaquim, em Salvador-BA, entre 4 horas e 7 horas, três vezes por semana. A circunstância em que tais mercadorias, trazidas por pequenos produtores agrícolas e extrativistas da cidade e do entorno, são expostas diretamente na pedra do calçamento ou no chão do local, sem mediação de qualquer tipo de mobiliário, deu origem ao nome Pedra, como é conhecida e referida a atividade pelos participantes e usuários.

Para efeito deste enfoque, denominamos de mercado das folhas o mecanismo de oferta-procura-preço, mediante o qual se pratica o comércio dessas mercadorias, destacando que tal mecanismo não ocorre apenas na Feira de São Joaquim, mas alcança outros lugares (Mercado das Sete Portas, Mercado de São Miguel, Centrais de Abastecimento de Salvador (CEASA) do Rio Vermelho, feiras de bairros populares, barracas e bancas de vendedores ambulantes dispersas pela cidade) e nem se restringe ao comércio exclusivo de folhas, além de raízes, cascas, frutos e sementes vegetais, também são vendidos produtos artesanais e vários itens da base material de práticas rituais afro-brasileiras - bonecos de pano para feitiço, folhas de bananeira sapecadas para acondicionamento de comida ritual, alguns tipos de alimentos como acaçá ${ }^{1}$ branco, broto de dendezeiro para confecção de mariwố $\hat{o}^{2}$, etc.

Seguindo o enfoque proposto por Karl Polanyi (2012) em sua análise do mercado como união de determinados traços institucionais, identificamos na configuração do Mercado da Pedra os seguintes elementos constitutivos:

i) um local físico, o Mercado da Pedra, na Feira de São Joaquim, que ocorre três vezes por semana, durante a madrugada, a partir do qual as mercadorias circulam por outros locais de troca dispersos pela cidade e região;

ii) as mercadorias disponíveis, certas espécies de plantas de uso ritual e/ou medicinal denominadas de folhas;

iii) um grupo ofertante, constituído por vendedores (os próprios produtores) de folhas, subdivididos em mateiros (extrativistas/coletores de espécies

\footnotetext{
1 O acaçá é uma iguaria afro-baiana feita de farinha de milho branco ou de arroz, cozida em ponto de gelatina e envolvida, ainda quente, em folhas de bananeira previamente sapecadas na chama, bastante utilizada na preparação de oferendas e composição de vários rituais do candomblé.

2 O mariwô, termo iorubá, é um adereço decorativo e ritual confeccionado apenas pelos homens, com a folha nova (e ainda não aberta) do dendezeiro (Elaeis guineensis) que, desfiada manualmente, fica com o aspecto de cortina ou franja, e é colocado sobre vãos de portas e janelas das edificações religiosas, com a função de demarcar o espaço sagrado e proteger umbrais e limiares.
} 
nativas que chamam de grossas) e horticultores (cultivadores de espécies mais frágeis e delicadas, chamadas de frias ou cheirosas);

iv) um grupo demandante de compradores, constituído por comerciantes (proprietários de barracas em feiras e mercados públicos e vendedores ambulantes em logradouros públicos) e consumidores finais (povo-de-santo, populares);

v) costumes ou normas que orientam e regulam as transações.

No contexto do Mercado da Pedra, portanto, se dão relações de troca (compra e venda), confrontando, de um lado, um grupo de compradores - comerciantes e consumidores finais -, e, do outro lado, um grupo de vendedores - pequenos agricultores e extrativistas -, na condição de produtores e fornecedores dessas mercadorias. Assim, o Mercado da Pedra funciona como centro distribuidor das folhas em Salvador-BA, abastecendo diversos postos do comércio varejista dessas mercadorias, dispersos pela própria Feira de São Joaquim e por outras feiras, mercados e logradouros da cidade.

A pesquisa que fundamentou este artigo foi realizada entre 2012 e 2015, tendo como interlocutores os agentes sociais envolvidos na produção, distribuição, circulação e consumo das folhas. Além do período de observação direta das atividades cotidianas praticadas no local, da coleta de dados primários e da realização de entrevistas com agentes do Mercado da Pedra e da Feira de São Joaquim, foram feitas incursões em áreas de produção das plantas. A observação direta e o registro etnográfico se concentraram nas transações mercantis matinais entre produtores e consumidores na Pedra.

\section{O Mercado da Pedra e seus Agentes}

Em Salvador, o comércio de plantas de uso ritual e terapêutico pelas religiões afro-brasileiras opera com duas categorias, denominadas pelos agentes sociais como folhas grossas e folhas frias/cheirosas. Desse modo, grossas define certas espécies de plantas nativas, não cultivadas, oriundas de áreas naturais (o mato), de onde são extraídas/coletadas pelos mateiros que detêm o conhecimento das espécies, enquanto o termo frias/cheirosas define as plantas cultivadas por horticultores em quintais domiciliares e pequenas hortas, sendo ambas objeto de amplo uso mágico-religioso e medicinal.

As transações que ocorrem na Pedra, portanto, são protagonizadas por (i) um grupo de dezenas de compradores conhecidos, constituído por 
comerciantes instalados em barracas, boxes e lojas de produtos religiosos afro-brasileiros e vendedores ambulantes, considerados como a clientela/ freguesia de (ii) um grupo de dezenas de fornecedores-vendedores de folhas grossas e cheirosas, na condição de mateiros e/ou de horticultores, e os raizeiros (TABELA 1), como se chamam os agentes que revendem raízes, cascas, sementes e outros itens ${ }^{3}$. Na Pedra também comparecem, com frequência habitual, (iii) alguns dos consumidores finais - povo-de-santo ${ }^{4}$ e populares - para adquirir folhas frescas e viçosas diretamente da mão dos produtores, sejam plantas rituais e/ou medicinais. Completando o quadro dos agentes sociais envolvidos nas transações, há também (iv) os carregadores, elementos fundamentais para o transporte e distribuição das mercadorias.

\begin{tabular}{cccc}
$\begin{array}{c}\text { TABELA } 1 \\
\text { e Sexo (N) }(\mathbf{m}) \text { - Mercado da }\end{array}$ \\
$\begin{array}{c}\text { Categoria de } \\
\text { Atividade }\end{array}$ & Masculino & Feminino & Total \\
\hline Total & $\mathbf{2 0}$ & $\mathbf{4 9}$ & $\mathbf{6 9}$ \\
Horticultor & 4 & 1 & 5 \\
Mateiro & 7 & 47 & 54 \\
Raizeiro & 9 & 1 & 10 \\
\hline
\end{tabular}

Fonte: Levantamento de Campo, 2012-2015

$\mathrm{Na}$ Pedra, entre as mercadorias comercializadas, predominam as folhas grossas. A quantidade de fardos destas, trazidas regularmente pelos mateiros suplanta a das folhas cheirosas dos horticultores e a dos itens dos raizeiros. A preponderância das folhas grossas se evidencia mesmo pelo número de fornecedores, os mateiros extrativistas/coletores, em que se destacam as mulheres.

Uma característica importante do Mercado da Pedra é a composição do grupo de vendedores de plantas de uso ritual/medicinal: os fornecedores, responsáveis pelo abastecimento do mercado de folhas em Salvador-BA, são os próprios produtores tanto os mateiros (extrativistas de plantas nativas), quanto os horticultores (pequenos agricultores de plantas delicadas em quintais ou hortas). Assim, não há intermediação de outros agentes entre os produtores diretos e os vendedores de folhas. Na Pedra não existe a figura do atravessador ${ }^{5}$, o sujeito que adquire a produção do pequeno produtor para comercializá-la em feiras e mercados, como é comum nas atividades

3 Entre tais itens úteis encontram-se objetos artesanais bastante procurados, como bonecos de pano (brancos, vermelhos e pretos), conhecidos como "bonecos de feitiço".

${ }_{4}$ Povo-de-santo é o termo genérico usado para se referir aos adeptos e praticantes do candomblé.

5 Com exceção do raizeiro, que não é o produtor da mercadoria que comercializa. 
agrícolas. O agente que pode ser classificado como atravessador, nessa acepção, é o comerciante retalhista, ou seja, o grupo de compradores que são comerciantes estabelecidos em pontos de venda fixos (boxes, barracas, lojas de mercados, de feiras ou de bairros) ou o vendedor ambulante, disperso pelas ruas da cidade. $\mathrm{Na}$ Pedra, incluem-se, portanto, nessa categoria, os habituais indivíduos que compram dos produtores as folhas em grandes quantidades para revendê-las, fracionadas, ao consumidor final, em lojas na própria Feira de São Joaquim ou em outros locais. Ressalte-se que na Pedra o consumidor final também compra, diretamente das mãos do produtor-vendedor, as folhas de que necessita para fins rituais e/ou terapêuticos, a preços mais em conta do que os do comércio retalhista.

$\mathrm{Na}$ época da pesquisa, a Pedra reunia, em dias de maior movimento, mais de uma centena de pessoas, incluindo os habituais fornecedores de folhas, sua clientela de compradores e consumidores, os poucos e indispensáveis carregadores da Feira, além de curiosos e vendedores-ambulantes. No entanto, a frequência dos mateiros e horticultores oscilava nas jornadas do Mercado: uns compareciam todos os dias e outros apenas uma ou duas vezes por semana. Tal flutuação na frequência dos produtores provocava, às vezes, pequenos transtornos aos compradores que ficavam sem os habituais fornecedores de mercadorias.

O movimento na Pedra começa por volta das 3 h30, quando chegam os primeiros mateiros e horticultores vindos de bairros periféricos da cidade (Cabrito, Palestina, São Cristóvão, Sete de Abril, Estrada Velha do Aeroporto etc.) e de locais da Região Metropolitana de Salvador, como Camaçari (Arembepe, Abrantes, Jauá), Lauro de Freitas (Areia Branca, Itinga), Simões Filho (Mapele, Cotegipe, Tiro Seguro) e Dias D'Ávila. Os mateiros usam as linhas do transporte coletivo urbano para trazer os fardos de folhas coletadas na véspera, numa jornada iniciada por volta das 2horas, 2h30, como relatam Helena e Dalva, mateiras de Mapele e Simões Filho:

[...] O dia de vim prá feira começa muito cedo porque o transporte passa [às] três horas da madrugada lá no ponto e a gente ainda tem que levar os fardos com as folhas de casa pro ponto do ônibus. (Helena, mateira de Mapele, entrevista, 2015).

[...] venho toda vez no transporte coletivo, tem um ônibus bem cedo da [empresa] Litoral Norte, a gente traz os pacotes das folhas tudo no ônibus. (...) me levanto às duas da madrugada prá estar no ponto antes de três e meia, com as folhas prá pegar a condução prá cá... aí chega aqui lá prás quatro horas, mais ou menos... (Dalva, mateira de Simões Filho, entrevista, 2015).

As mercadorias trazidas pelos mateiros vêm acondicionadas em grandes fardos de 40 quilos cada um, contendo de 80 a 100 molhos de diversas espécies de folhas. Para envolver tal volume de folhas, os mateiros reutilizam embalagens 
industriais do tipo saco de ráfia, usadas para a comercialização de produtos como rações, cereais e sementes. As embalagens vazias, em forma de sacos, são abertas, transformando-se no que os mateiros chamam de panos, bastante disputados para acondicionar e transportar as mercadorias vendidas.

Geralmente seguindo de perto o transporte dos fardos de folhas pelos carregadores ou, por vezes, carregando suas próprias mercadorias, os fornecedores adentram a área do mercado e logo ocupam os lugares habituais. Embora o arranjo resultante da ocupação do espaço na Pedra pelos produtores estabeleça, nitidamente, três grupos distintos de vendedores, a inclusão de cada um em determinado grupo não é rígida, observando-se uma flutuação nessa composição. O arranjo espacial não tem forma racionalmente estabelecida: os pontos de venda se aglutinam, lado a lado, deixando uma estreita passagem para circulação de compradores entre os montes de folhas caprichosamente arrumadas no chão, em camadas superpostas por espécie de planta, atrás das quais se postam, ficando de pé por até quatro horas. Como afirma Tia Elzira:

[...] a gente chega e vai arrumando no chão mesmo, cada monte por qualidade da folha, uma do lado da outra, compreende? Separadas por qualidade. (Tia Elzira, mateira de Dias D'Ávila, entrevista, 2015).

Assim, as pilhas de espécies distintas de folhas de cada produtor expostas lado a lado, vão definindo, a cada momento, uma amostra precisa da diversidade de plantas disponíveis em cada jornada da Pedra. À medida em que chegam, os mateiros vão cobrindo a pavimentação do local com suas folhas que, àquela hora da madrugada, exalam um aroma de mato, naturalmente agradável e que a brisa marinha espalha por todo o ambiente, sobrepondo-se ao habitual e característico odor fermentado de frutas, verduras e restos impregnantes de toda feira.

\section{Mercado, Produção e Circulação das Folhas}

$\mathrm{Na}$ Pedra, tudo gira em torno das folhas. O mercado das folhas em SalvadorBA abrange os domínios da produção (e distribuição ${ }^{6}$ ), da circulação (troca) e do consumo dessas mercadorias, envolvendo diversos agentes sociais e suas interações recíprocas nesses contextos. Sua configuração compreende três estruturas sociais bem definidas: a) a produção/distribuição; b) a circulação e $c$ ) o consumo (DIAGRAMA 1).

\footnotetext{
6 Usamos, aqui, o termo distribuição no sentido do provimento da mercadoria folha pelos produtores (mateiros e horticultores) no Mercado da Pedra, onde os comerciantes se abastecem regularmente.
} 
DIAGRAMA 1 - Configuração do Mercado das Folhas em Salvador

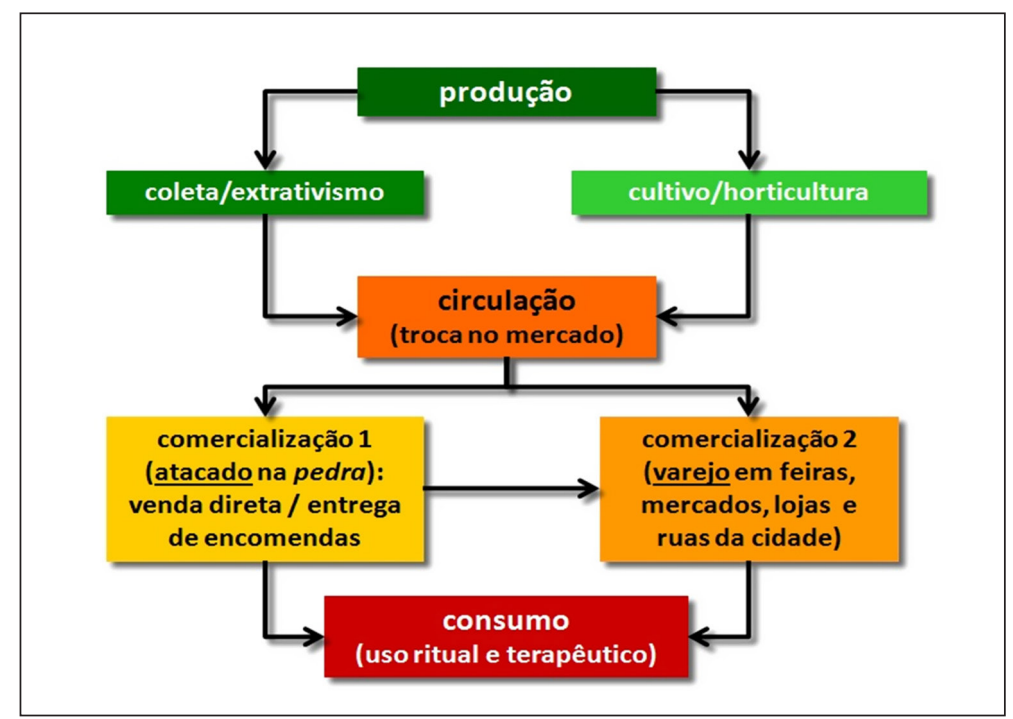

Fonte: Elaborado pelo autor, 2014.

A estas estruturas correspondem determinados agentes sociais envolvidos nas atividades aí desenvolvidas (DIAGRAMA 2). Além disso, a esfera da produção abrange duas categorias de produtos, as folhas grossas e as folhas cheirosas/frias, que resultam de distintos processos de produção (coleta-extrativismo e cultivohorticultura, respectivamente) e a que se relacionam também agentes sociais específicos - mateiros e horticultores -, responsáveis pela produção e fornecimento regular dessas mercadorias ao Mercado da Pedra.

DIAGRAMA 2 - Agentes sociais do mercado das folhas

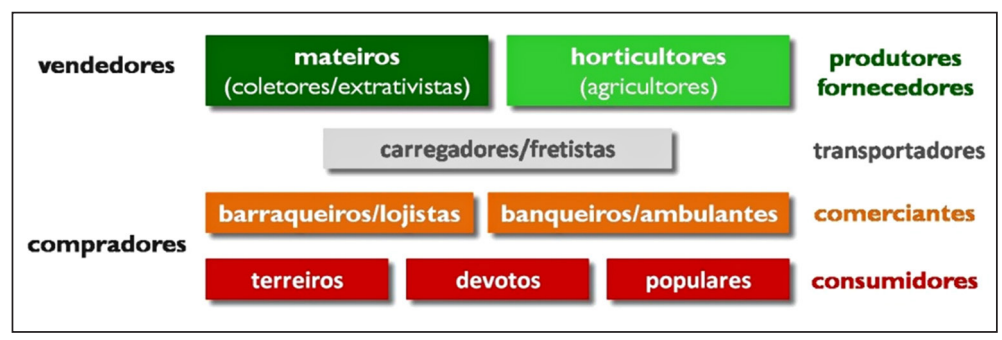

Fonte: Elaborado pelo autor, 2014

Os agentes sociais da produção são, os mateiros, trabalhadores informais que se ocupam de atividade extrativista para coletar determinadas espécies de plantas 
nativas em áreas de manchas florestais remanescentes, às margens de estradas e vias urbanas, suburbanas e rurais - a que chamam de mato -, e os horticultores, pequenos agricultores que cultivam outras espécies de plantas, domesticadas, mais frágeis e delicadas, em hortas e/ou quintais domiciliares. O mateiro e o horticultor, utilizandose de práticas específicas (extrativismo e cultivo), são, assim, os produtores e fornecedores das folhas grossas e frias/cheirosas que abastecem o Mercado na Feira de São Joaquim, iniciando o circuito de trocas que as folhas fazem, enquanto valores de troca (VT), até saírem da condição de mercadorias, ao serem vendidas para serem consumidas. Aqui, já na esfera do consumo, em comunidades religiosas de terreiros de candomblé ou na privacidade dos domicílios, as folhas se efetivam como valores de uso (VU). Marx (2013) assinala essa passagem da mercadoria entre os domínios (circulação e consumo) como metabolismo social:

$\mathrm{Na}$ medida em que o processo de troca transfere mercadorias de mãos em que elas não são valores de uso para as mãos em que elas são valores de uso, ele é metabolismo social. [...]. Quando passa a servir de valor de uso, a mercadoria transita da esfera da troca de mercadorias para a esfera do consumo. (MARX, 2013, p. 178).

A produção dessas mercadorias articula-se com o seu consumo, na medida em que as práticas rituais das comunidades religiosas afro-brasileiras estabelecem a demanda das espécies prescritas e necessárias aos usos rituais. Sabe-se que certas espécies de plantas são consideradas constituintes de fundamentos e preceitos, cercadas de segredos, com cultivo restrito às áreas de mato dos terreiros. Há até um circuito de trocas e permutas de mudas e sementes de plantas entre as comunidades religiosas para sanar o problema da escassez de áreas verdes naturais.

A circulação dessas mercadorias tem início com as trocas no mercado e se efetivam em duas formas de comercialização, em locais e momentos também distintos. A primeira forma, que chamamos de comercialização 1 (DIAGRAMA 1) constitui o momento inicial de todo o processo das trocas, quando os próprios produtores, na condição de fornecedores, levam suas mercadorias a São Joaquim e na Pedra praticam a venda no atacado (embora também ocorra no varejo) ${ }^{7}$. A venda no atacado se processa de duas formas: a venda direta, feita na hora em que aparece o comprador, geralmente um comerciante já conhecido do mateiro ou do horticultor, que lhes compra grandes quantidades de folhas para revender; e a venda por encomenda, que consiste no fornecimento, previamente acordado, de grandes quantidades de folhas, cuja entrega é feita diretamente aí ou é despachada para serem

\footnotetext{
7 É o caso do povo-de-santo ou de fregueses populares, que lhes compram poucas quantidades, comparadas as dos comerciantes.
} 
transportadas, por fretistas, para os destinatários em outros locais. Os compradores que aí comparecem são tanto os comerciantes estabelecidos em feiras, mercados e lojas e em bancas de rua (vendedores-ambulantes conhecidos de erveiros/raizeiros), quanto os consumidores comuns, geralmente membros e/ou devotos de religiões afro-brasileiras e/ou populares.

A segunda forma, comercialização 2 (DIAGRAMA 1), consiste no comércio propriamente retalhista de folhas, isto é, a venda, no varejo ou a retalho, de pequenos molhos que resultam do fracionamento dos molhos originais comprados de mateiros e horticultores, e que é praticado, cotidianamente, nas barracas de outras feiras e mercados, em lojas e bancas de rua. O comércio informal, o pequeno negócio a partir de bancas de folhas, encontra-se espalhado por toda cidade, em áreas nobres como Barra e Graça, em bairros populares - Federação, Engenho Velho da Federação e de Brotas, Nordeste de Amaralina, Liberdade -, e em áreas comerciais do Centro, como Largo 2 de Julho, Forte de São Pedro, Avenida Sete, Relógio de São Pedro, Barroquinha, Baixa dos Sapateiros etc.

Nas transações da Pedra os produtores-vendedores e os carregadores/fretistas são, de fato, os responsáveis pela distribuição e abastecimento das folhas no mercado $^{8}$, sem a presença de atravessadores (DIAGRAMA 2). A esfera do consumo, que ocorre totalmente fora da circulação no mercado, envolve as comunidades religiosas afro-brasileiras (povo-de-santo dos candomblés e outros fiéis/devotos) com suas formas singulares de uso ritual e também uma expressiva parcela da população, principalmente os mais pobres, com suas formas tradicionais de uso terapêutico. Para Marx (2013, p. 228), "a circulação simples de mercadorias - a venda para a compra - serve de meio para uma finalidade que se encontra fora da circulação, a apropriação de valores de uso, a satisfação de necessidades". Nessa última esfera, as folhas já transitam fora do estado de mercadoria, agora imersas no mundo da religiosidade, propriamente integradas ao sistema da dádiva, sob as formas ritualizadas de oferendas às divindades (os orixás) ou de práticas terapêuticas fitoterápicas tradicionais.

Seguindo a tipologia elaborada por Appadurai (2010, p 31), as folhas, tal como se encontram contemporaneamente inseridas no mercado, podem ser compreendidas como "mercadorias por metamorfose", na categoria de "coisas destinadas a outros usos que se colocam no estado de mercadorias". Neste sentido, as folhas, enquanto coisas portadoras de valor de uso (ritual/medicinal) para comunidades religiosas afro-brasileiras e para a população em geral, entram em estado de mercadoria ao serem levadas ao mercado, adquirindo valor de troca para os seus produtores, os

8 Gorender (1996) afirma que para Marx, o transporte da mercadoria, bem como sua armazenagem e distribuição, é atividade necessária ao processo de produção ou que o prolonga na esfera da circulação, sendo considerada produtiva. 
mateiros e os horticultores que as vendem para outros vendedores que, por sua vez, as revendem para os consumidores. Em seguida, ao serem compradas pelo consumidor final, as mercadorias saem da circulação e efetivam seu valor de uso ao serem consumidas como coisas úteis, na esfera do consumo religioso dos terreiros, onde são submetidas a novas transformações, de caráter mágico, que provocam o avivamento da sua eficácia ${ }^{9}$, do seu $a x e^{10}$, ou na esfera do consumo terapêutico dos domicílios particulares, onde são revestidas de sentidos e significados curativos tradicionais. (Maupoil apud BASTIDE, 2001, p. 77).

\section{Sobre o mercado, a produção e a circulação}

Quando falamos de mercado, nos referimos a dois sentidos implícitos e diferentes do termo que definem também "dois tipos de entidades: um conceito econômico e uma realidade empírica”, como afirma Meunier (1978, p. 240). Inicialmente, enquanto realidade empírica, o mercado implica um lugar específico, segundo Polanyi (2012, p. 183), "tipicamente, um local aberto, onde as necessidades da vida, em especial alimentos frescos ou preparados, podem ser compradas em pequenas quantidades, em geral por valores predeterminados". Para Meunier (1978, p. 241), além de designar o local "onde se efectua um certo número de transações", o mercado é "onde se reúnem todos os que querem ceder, adquirir ou trocar produtos, sob a forma de troca directa ou utilizando moeda". Assim, no sentido empírico, concreto, falamos de mercado-local, dos mercados públicos de Salvador-BA, a exemplo dos Mercados de São Miguel e de Santa Bárbara, na Baixa dos Sapateiros, dos privados, como o Mercado das Sete Portas, ou dos mercados setoriais, como o Mercado do Peixe (Popular), na Água Brusca, e o Mercado da Pedra, na Feira de São Joaquim.

No segundo sentido, mais abstrato, enquanto conceito econômico, o termo mercado compreende, segundo Polanyi (2012, p. 183), "um mecanismo de ofertaprocura-preço por meio do qual se realiza o comércio, embora esse mecanismo não esteja necessariamente preso a um local definido nem se restrinja à comercialização de alimentos". Meunier (1978, p. 240) considera que "na teoria econômica clássica, o mecanismo do mercado caracteriza-se pela interacção da oferta e da procura solventes, que determinam as taxas a que são trocadas as mercadorias e, em contrapartida, as decisões de produção".

\footnotetext{
9 Para Braga (2000), o avivamento das folhas consiste na restituição de suas propriedades mágicoreligiosas e medicinais, mediante processos rituais, com emissão de encantações (ofó).

${ }^{10}$ Axé é o termo iorubá para designar "a força invisível, a força mágico-sagrada de toda divindade, de todo ser animado, de todas as coisas", equivalente da baraka magrebina, do mana polinésio e melanésio, da orenda dos iroqueses, do manitu dos algonquinos (Maupoil apud BASTIDE, 2001, p. 77).
} 
No sentido mais abstrato do termo, podemos falar do mercado das folhas em Salvador-BA, cuja configuração envolve um centro de abastecimento das mercadorias (Feira de São Joaquim), a partir do qual são distribuídas por um conjunto de estabelecimentos de comercialização no atacado e no varejo, incluindo a própria Feira e outros mercados e pontos de venda. O mercado das folhas abrange mecanismos específicos de comércio de plantas rituais e medicinais, a saber, $i$ ) produtores, ii) fornecedores, iii) transportadores, iv) vendedores, $v$ ) compradores e vi) consumidores, além, obviamente, das próprias mercadorias, vii) as folhas. A singularidade desse mercado de folhas em Salvador-BA já se insinua na acumulação de funções por parte de alguns dos agentes sociais envolvidos: os produtores da mercadoria, os mateiros e os horticultores são os próprios fornecedores que abastecem o mercado e que, ao mesmo tempo, também desempenham a função de vendedores dessa produção. Aqui, entre a produção e a circulação (troca), não comparece a figura, frequente em muitos mercados, do intermediário, o típico atravessador que açambarca toda a produção antes que essa chegue ao mercado. $\mathrm{Na}$ situação de troca mercantil, estes produtores vendem suas mercadorias a quem as queira comprar, sejam compradores estabelecidos em estruturas de comercialização distribuídas em várias feiras e mercados públicos (os chamados barraqueiros), grupos dispersos de vendedores avulsos (os chamados raizeiros/erveiros ambulantes), ou compradores comuns, os consumidores finais, representados pelo povo-de-santo e pela população em geral, usuária de plantas medicinais.

A partir da chegada das folhas ao Mercado da Pedra se iniciam as transações de compra e venda que deflagram o processo de circulação dessas mercadorias. Do ponto de vista dos produtores-fornecedores - os mateiros e os horticultores -, sua atividade mercantil começa com a venda das folhas e termina quando, com o dinheiro da venda, compram outras mercadorias de que necessitam. Para Marx (2013, p. 223) esta é "a forma imediata da circulação de mercadoria", sintetizada no esquema "( $\mathrm{M}-\mathrm{D}-\mathrm{M})$, conversão de mercadoria em dinheiro e reconversão de dinheiro em mercadoria, vender para comprar” (DIAGRAMA 5).

DIAGRAMA 5 - Circulação simples da mercadoria

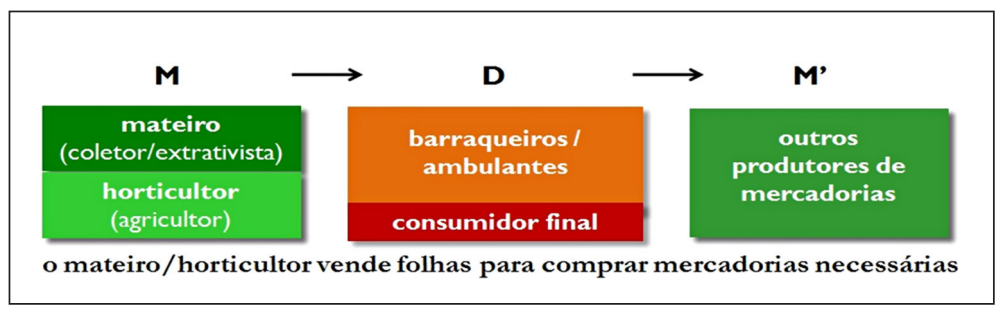

Fonte: Elaborado pelo autor, 2014 
Assim, o produtor vende a mercadoria folha, realizando sua troca por dinheiro, tornando-se, a partir de então, comprador de outras mercadorias para satisfazer necessidades, retirando-as da circulação. No primeiro momento dessa circulação, ou seja, no momento da venda $(\mathrm{M}-\mathrm{D})$, aparece a figura do comprador que, ao adquirir a mercadoria para (re)vendê-la a outrem, a retira da circulação simples para lançá-la na outra forma, a circulação desenvolvida ou circulação do dinheiro como capital (DIAGRAMA 6).

\section{DIAGRAMA 6 - Circulação desenvolvida (do dinheiro como capital)}

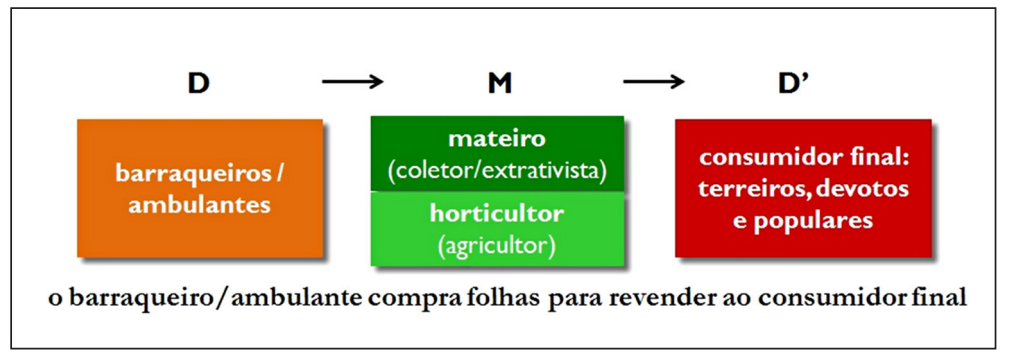

Fonte: Elaborado pelo autor, 2014.

No contexto do mercado das folhas em Salvador, esse comprador é a peça chave na circulação da mercadoria, a partir do Mercado da Pedra, pelo fato de atuar como o elemento que possibilita, por sua atividade de comerciante, a articulação da Pedra com outros circuitos de troca, representados pelas redes de comércio retalhista distribuídas pela cidade, em mercados, feiras e bancas de rua. Em momentos posteriores, ao serem compradas, como valores de uso, essas mercadorias saem da circulação para adentrarem a esfera do consumo, alcançando assim o seu destino de utilidade ${ }^{11}$.

Ainda analisando a primeira forma do circuito de trocas $(M-D-M)$, em seu primeiro movimento $(\mathrm{M}-\mathrm{D}$, a venda), observa-se que o comprador a quem o produtor vende suas folhas, pode representar duas categorias distintas de agentes. Primeiro, pode ser o consumidor final da mercadoria (DIAGRAMA 7), para quem esta possui valor de uso, e aí, nesse primeiro momento, se encerra a circulação do produto e o valor de uso tem sua realização efetiva - a folha é consumida como erva sagrada, mágico-religiosa e/ou como remédio fitoterápico natural e este consumo ocorre fora do mercado.

O outro caso é quando o comprador é o comerciante, para quem a mercadoria possui valor de troca, sendo por ele fracionada antes de revendê-la em outros

\footnotetext{
11 "Na primeira metade de sua circulação, a mercadoria troca de lugar com o dinheiro. Com isso, sua forma de uso sai da circulação e entra no consumo." (MARX, 2013, pp. 188-189).
} 
mercados. Aqui este agente faz a mediação entre as duas formas de circulação, sendo, neste caso, o representante da circulação desenvolvida, o capitalista que compra mercadoria para $\left(\right.$ re) vender $\left(\mathrm{D}-\mathrm{M}-\mathrm{D}^{\prime}\right)^{12}$, realizando nesse circuito a obtenção do mais valor da mercadoria.

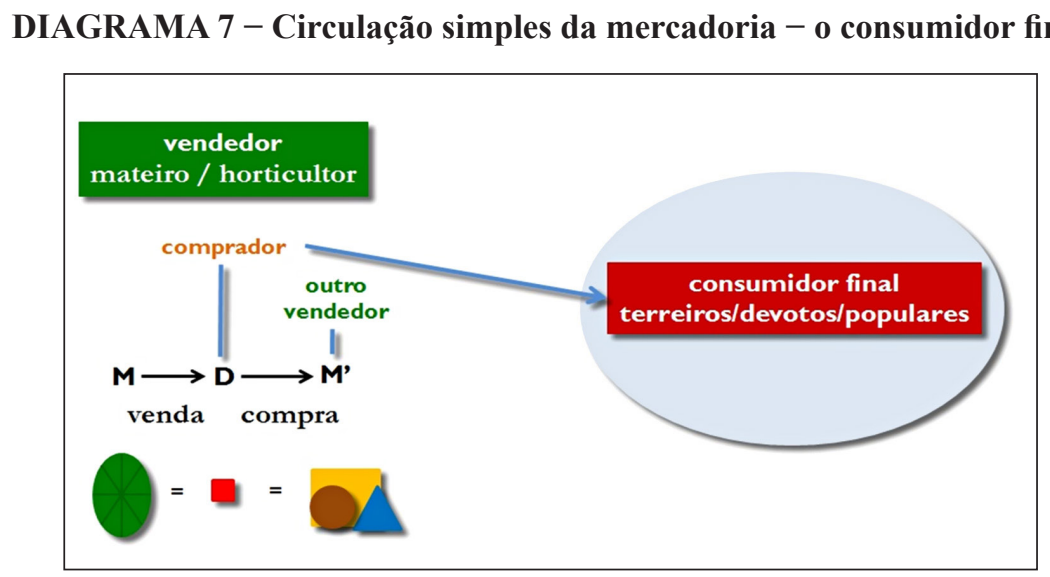

Fonte: Elaborado pelo autor, 2014.

A esfera da circulação simples envolve os agentes sociais produtores da mercadoria folha, - os mateiros e os horticultores - na condição de vendedores e na condição de compradores, os consumidores, representados majoritariamente pelos comerciantes e, secundariamente, pelo povo-de-santo e pessoas comuns.

\section{DIAGRAMA 8 - Circulação simples da mercadoria - o comerciante retalhista}

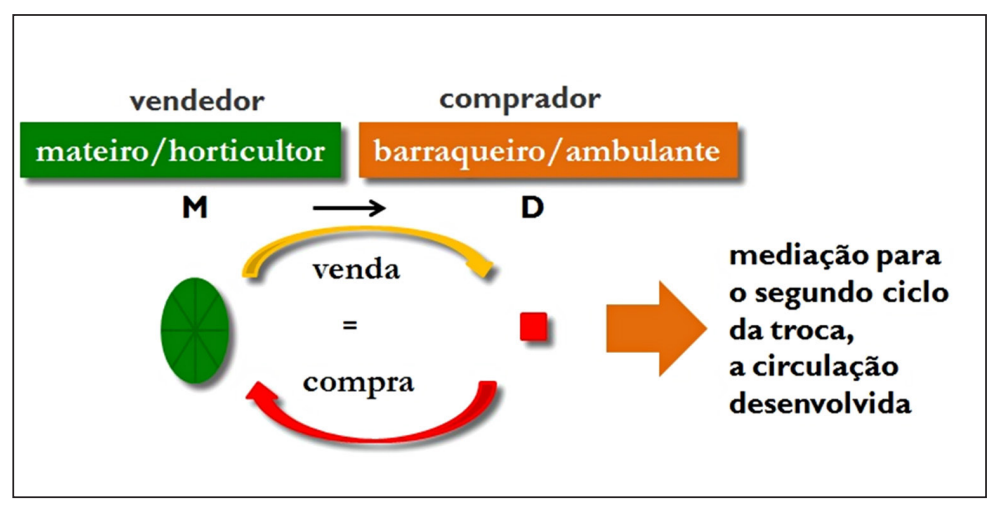

Fonte: Elaborado pelo autor, 2014.

12 'A forma completa desse processo é, portanto, $D-M-D$ ', onde $D$ ' $=D+\Delta D$, isto é, a quantia de dinheiro inicialmente adiantada mais um incremento. Esse incremento ou excedente sobre o valor original, chamo de mais valor (surplus value)." (MARX, 2013, p. 227), [grifo do autor]. 
Vê-se aqui a demonstração empírica da metamorfose da mercadoria quando se encontram os "três personae dramatis" referidos por Marx (2013, p. 185) envolvidos no processo de circulação que ocorre durante a negociação no Mercado da Pedra: os possuidores de mercadoria (folhas), os mateiros e horticultores que se confrontam, enquanto vendedores, com os possuidores de dinheiro, os comerciantes/barraqueiros, na condição de compradores. Resulta daí a primeira metamorfose da mercadoria: a folha transforma-se em dinheiro. No segundo ciclo do processo da troca que se inicia, o mateiro/horticultor, que era um vendedor no primeiro ciclo, agora, enquanto possuidor de dinheiro, torna-se um comprador de mercadorias de um terceiro vendedor, possuidor de outras mercadorias de que ele necessita, fazendo ocorrer a segunda metamorfose da mercadoria, isto é, a transformação do dinheiro em outras mercadorias. Venda e compra se alternam durante o processo de troca:

Como ponto de chegada da primeira mutação da mercadoria, o dinheiro é, ao mesmo tempo, o ponto de partida da segunda mutação. Assim, o vendedor do primeiro ato torna-se comprador no segundo, onde um terceiro possuidor de mercadorias confronta-se com ele como vendedor.

Os dois movimentos inversos da metamorfose da mercadoria formam um ciclo: forma-mercadoria, despojamento da forma-mercadoria, retorno à formamercadoria. (MARX, 2013, p. 185).

Do ponto de vista da circulação dessas mercadorias, ainda usando as categorias de Marx (2013), observa-se, assim, a coexistência e a justaposição de duas esferas que se interpenetram nessa configuração do mercado das folhas em Salvador-BA: a forma simples de circulação e a circulação desenvolvida ou circulação do dinheiro como capital (DIAGRAMA 9). Ou seja, em sua forma simples de circulação, o mercado de folhas contém aspectos de um mercado tradicional, evidenciados pelo padrão de negociação realizado na Pedra, caracterizado pela troca mercantil, ou troca monetarizada, envolvendo os agentes primários da troca, os próprios produtores (mateiros e horticultores) como vendedores e os compradores (comerciantes, devotos e populares, consumidores). 
DIAGRAMA 9 - Esferas de circulação de mercadorias no Mercado de Folhas

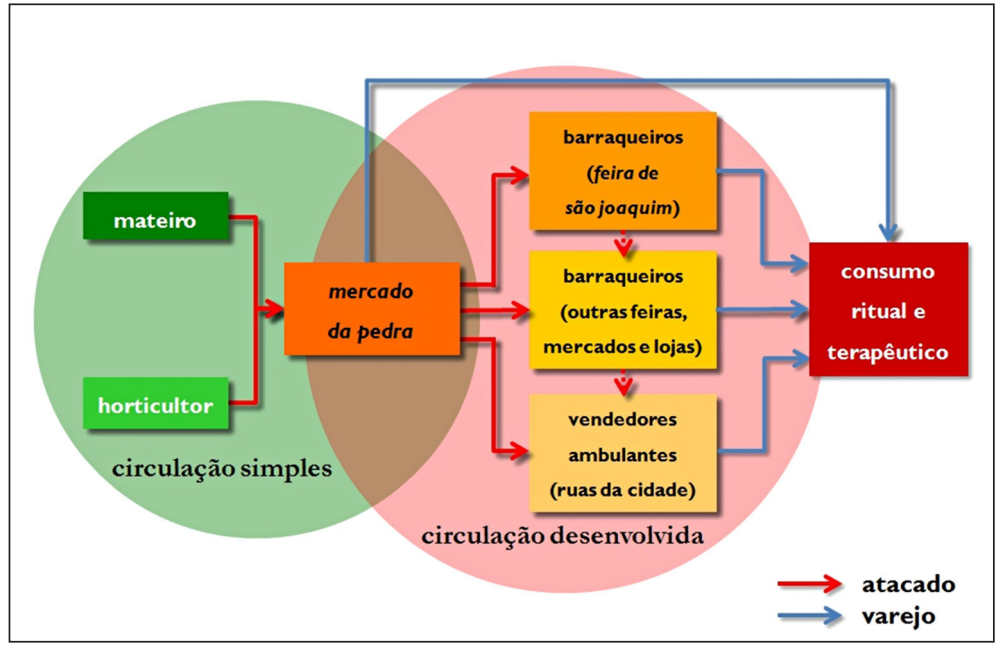

Fonte: Elaborado pelo autor, 2014.

Em um ambiente de intensa sociabilidade e de interações ancoradas em relações de parentesco, afinidade, amizade e vizinhança, a Pedra acaba por revelar a imersão da atividade econômica, que é a base da sobrevivência daqueles homens e muitas mulheres, no universo da vida social, cultural e espiritual desses agentes do mercado. Seria um exemplo empírico do embeddedness (enraizamento social da economia), segundo a formulação substantiva de Polanyi (2012)? O ambiente alegre e festivo da feira, a demanda das folhas orientada pelas práticas rituais das religiões de matriz africana e pelos modos distintos de consumo encontram aqui forte elo de ligação e aproximação com os mercados tradicionais africanos, descritos por Verger e Bastide (1992). O clima comunitário e amistoso do Mercado da Pedra, observável nas relações de cooperação e reciprocidade praticadas pelos produtores-fornecedores, e, especialmente, pelos mateiros, por outro lado, nos faz questionar o caráter de competitividade e concorrência que normalmente se associa ao comportamento (racional e maximizador) dos agentes do mercado. Weber (1999, p. 420), embora se refira à "comunidade de mercado", enfatiza o seu caráter de estranhamento "já na raiz, a toda confraternização".

Identifica-se aí no Mercado da Pedra a forma imediata da circulação das mercadorias, uma das "duas formas distintas de ciclos" apresentadas pelo processo de circulação, segundo Marx (2008, p. 119), que corresponde ao primeiro circuito da metamorfose da mercadoria, representado pelo esquema clássico $\mathrm{M}-\mathrm{D}-\mathrm{M}$, mas, simultaneamente, pode-se verificar a mediação do comerciante dono de barraca ou loja do comércio retalhista que dá início ao segundo ciclo do processo de circulação, 
a circulação desenvolvida ou a circulação do dinheiro como capital. Arcaico e moderno aí coexistem e evidenciam a singularidade do Mercado da Pedra. Tudo começa na Pedra, provavelmente numa herança de antigos e extintos mercados soteropolitanos, anteriores e contemporâneos da formação do candomblé jeje-nago, e se dissemina pelo circuito de feiras, mercados e bancas da cidade.

\section{Conclusão}

Neste artigo examinamos a configuração de um mercado em que a cultura e as formas da tradição religiosa afro-brasileiras partilham significados, identidades, práticas cotidianas e normas localmente enraizadas, socialmente construídas por grupos sociais que, embora não constituam uma comunidade strictu sensu, o são em situação de convivência e forte interação social, decorrente das alternativas de reprodução social de que se valem, indo ao mercado.

Analisando sua configuração geral, o mercado de plantas rituais em SalvadorBA é composto por duas esferas interdependentes e complementares de circulação de mercadorias, cujas respectivas estruturas têm graus diferenciados de complexidade. Em síntese, pode-se dizer que coexistem, lado a lado, uma esfera de circulação simples de mercadoria, representada, sobretudo, pelas transações de compra e venda realizadas durante a madrugada no Mercado da Pedra, quando os próprios produtores (mateiros e horticultores) vendem folhas grossas e frias em grandes quantidades a compradores habituais (feirantes, ambulantes e consumidores avulsos), e uma esfera de circulação desenvolvida, representada pela rede de comércio retalhista que envolve comerciantes da própria Feira de São Joaquim e de outras feiras e mercados da cidade, além de comerciantes de lojas e vendedores ambulantes dispersos pela cidade.

Do ponto de vista dos produtores-fornecedores que abastecem o Mercado da Pedra com plantas rituais/medicinais, sua atividade se finda com a venda da mercadoria trazida para seus contumazes compradores que a retiram da circulação simples. A jornada do Mercado da Pedra, na efêmera duração de 3 ou 4 horas, põe em circulação quantidades consideráveis de itens vegetais, cujo processo de apropriação social na natureza, segundo determinações de consumo mágico-religioso e terapêutico, emanadas da esfera das religiões afro-brasileiras, os conduz ao estado de mercadoria ${ }^{13}$, fazendo entrecruzar-se os âmbitos da economia e da cultura.

\footnotetext{
${ }_{13}$ No estado de mercadoria, o valor de uso e valor de troca coexistem dialeticamente na folha, que na Pedra é, simultaneamente, bem econômico e simbólico significativo para os agentes sociais envolvidos em sua produção, circulação e consumo.
} 
Quanto à questão do lucro nas vendas (pelo comerciante retalhista), percebese que resulta tanto da diferença entre o preço de compra e o de (re)venda, quanto da medida (porção) do produto na compra e na revenda (ao revender a folha, o retalhista fraciona o molho adquirido em até oito pequenos molhos, vendendo-os a um preço três vezes superior ao do molho comprado, produzindo, ao final, um ganho superlativo). Dessa forma, ao explorar as oportunidades de um mercado tradicional, os comerciantes de grandes quantidades contribuem, com suas práticas capitalistas, para a persistência daquele mercado africano (apesar da evidente situação de dependência), e, por conseguinte, asseguram o atendimento das determinações da demanda da tradição religiosa afro-brasileira na contemporaneidade.

Contudo, aquela comunidade de mercado, composta por grupos de indivíduos conhecidos e habituais - produtores-vendedores, consumidores-compradores de grandes e pequenas quantidades de folhas - cria uma estrutura social. De fato, os agentes sociais do Mercado da Pedra se envolvem, a cada jornada, em relações sociais baseadas na confiança mútua, na cooperação, na amizade e na dependência, mais duradouras que o efêmero contrato implícito do ato de compra/venda. A reciprocidade e a solidariedade evidenciadas, por exemplo, nas práticas cotidianas do empréstimo $^{14}$ de folhas entre as mateiras, são alguns dos laços sociais tradicionais ${ }^{15}$ que, opondo-se à impessoalidade, à competição e à concorrência características do mercado capitalista, segundo a análise weberiana clássica, aproximam-no do contexto dos mercados africanos. A convivência relacional e complementar de estruturas tradicionais e modernas tem, portanto, no Mercado da Pedra, na Feira de São Joaquim, sua expressão singular nas transações envolvendo as folhas de uso ritual e/ou medicinal.

\title{
The CONFIGURATION OF THE LEAF market in Pedra in Salvador
}

\begin{abstract}
This article analyzes the configuration of the ritual / medicinal plants' (leaves) market used in the candomble of Salvador, from the circulation of these goods as they are produced and commercialized by foragers and horticulturalists who bring them regularly to the Feira de São Joaquim, the city's main distribution center for other circuits of retail commerce (fairs, marketplaces, stores and sale
\end{abstract}

\footnotetext{
${ }_{14}$ Quando compram entre si, mediante empréstimos que visam a atender a encomenda do comerciantecomprador, as mateiras estreitam o vínculo social entre elas. Como fala Helena, mateira de Mapele, "eu compro das colegas, eu ajudo elas, elas me ajuda, é assim." (Entrevista, 2015).

${ }^{15}$ A hegemonia feminina, a importância das relações de parentesco, o etnoconhecimento das plantas e sua transmissão intergeracional pela tradição oral são alguns aspectos convergentes com as matrizes sociais africanas desses grupos sociais.
} 
stands on the streets). The Mercado da Pedra, where large quantities of product are sold wholesale, takes place at dawn, and was the empirical basis for the ethnographic research, that made it possible to understand the social structures and agents involved in the production, distribution and consumption of the leaves that result from gathering (foraging) or harvesting (horticulture), of especially cultivated areas and gardens, as well as from natural areas, mainly the remaining native woodlands in the areas surrounding Salvador and in the interior of the state. The uniqueness of the leave's market in Salvador is revealed, amongst other factors, by the juxtaposition of the two spheres of distribution (simple and developed, as established by Marx) that interlace themselves dynamically, connecting a traditional market (of African making) to the contemporary capitalist market.

KEYWORDS: Ritualistic/medicinal plants. Market. African-brazilian religions.

\section{REFERÊNCIAS}

APPADURAI, A. A Vida Social das Coisas: as mercadorias sob uma perspectiva cultural. Niterói: Editora da UFF, 2010.

BASTIDE, R. O Candomblé da Bahia: rito nagô. São Paulo: Companhia das Letras, 2001.

BRAGA, J. Oritamaejí: o antropólogo na encruzilhada. Feira de Santana: Universidade Estadual de Feira de Santana, 2000.

GORENDER, J. Apresentação. In: MARX, K. O Capital - Crítica da Economia Política. São Paulo: Nova Cultural/Círculo do Livro, 1996. v. I, Livro Primeiro (O Processo de Produção do Capital), Tomo 1.

MARX, K. O Capital. Crítica da Economia Política. Livro 1: O processo de produção do capital. São Paulo: Boitempo, 2013. vol. I.

. Contribuição à Crítica da Economia Política. 2 ed. São Paulo: Expressão Popular, 2008.

MEUNIER, R. Formas da Circulação. In: POUILLON, F. (dir.). A Antropologia Econômica: correntes e problemas. Lisboa: Edições 70, 1978. p. 203-252.

POLANYI, K. A Subsistência do Homem e ensaios correlatos. Rio de Janeiro: Contraponto, 2012.

VERGER, P.; BASTIDE, R. Contribuição ao estudo dos mercados nagôs do Baixo Benin. In: VERGER, P. Artigos. São Paulo: Corrupio, 1992. p. 122-159. 
WEBER, M. Economia e Sociedade: fundamentos da sociologia compreensiva. Brasília, DF: Editora Universidade de Brasília; São Paulo: Imprensa Oficial do Estado de São Paulo, 1999. v. 1.

Recebido em 14/08/2017.

Aprovado em 23/11/2017. 
